\title{
Reduced alternative splicing of estrogen receptor alpha in the endometrium of women with endometriosis
}

\author{
Ying Zhang ${ }^{1,2, *}$, Yong Zhang ${ }^{1,2, *}$, Chunbo Zhao ${ }^{3}$, Tiantian Yu ${ }^{1}$, Ye Liu ${ }^{1,2}$, Weihui Shi ${ }^{1,2}$, \\ Fengtao Shi ${ }^{1,2}$, Xinmei Liu ${ }^{1,2}$, Jianzhong Sheng ${ }^{4,5}$, Hefeng Huang ${ }^{1,2,4}$ and Hong $\mathrm{Xu}^{1}$ \\ ${ }^{1}$ International Peace Maternity and Child Health Hospital, School of Medicine, Shanghai Jiao Tong University, The China \\ Welfare Institute, Shanghai, China \\ ${ }^{2}$ Institute of Embryo-Fetal Original Adult Diseases, School of Medicine, Shanghai Jiao Tong University, Shanghai, China \\ ${ }^{3}$ Department of Obstetrics and Gynecology, The Second Affiliated Hospital (Jiande Branch), Medical School of Zhejiang \\ University, The First People's Hospital of Jiande, Hangzhou, China \\ ${ }^{4}$ The Key Laboratory of Reproductive Genetics, Ministry of Education (Zhejiang University), Hangzhou, China \\ ${ }^{5}$ Department of Pathology and Pathophysiology, School of Medicine, Zhejiang University, Hangzhou, China \\ *These authors contributed equally to this work
}

Correspondence to: Hefeng Huang, email: huanghefg@hotmail.com Hong Xu, email: xuhong1168@126.com

Keywords: $E R a$; endometriosis; splice variant; dysmenorrhea

Received: March 21, $2017 \quad$ Accepted: October 11, 2017

Published: November 27, 2017

Copyright: Zhang et al. This is an open-access article distributed under the terms of the Creative Commons Attribution License 3.0 (CC BY 3.0), which permits unrestricted use, distribution, and reproduction in any medium, provided the original author and source are credited.

\section{ABSTRACT}

Endometriosis is a condition which involves the presence of uterine stroma and glands outside of the uterine cavity and represents one of the most prevalent disorders of the female reproductive tract. The key symptom of endometriosis is pain, including dysmenorrhea, deep dyspareunia, and chronic pelvic pain. As such, endometriosis has significant economic consequences within the healthcare system and can influence the daily quality of life in affected patients. However, the pathophysiology of this disease and the mechanisms in which this condition generates pain are very unclear. This study, involving $\mathbf{3 0}$ women with endometriosis and $\mathbf{2 8}$ controls without endometriosis, aimed to investigate relative levels of estrogen receptor alpha (ERa) splice variants in the endometrium of women with and without endometriosis and investigate potential links to the severity of pain. Wild type (wt)-ERa was dominantly expressed in human endometrium while the expression of ERa-del.4, ERa-del.7, and ERa-del.3,4 was significantly reduced in endometriosis patients compared with healthy patients $(p<0.05)$. Furthermore, the relative ratios of wtERa:ERa-del.4, and wtERa:ERa-del.3,4 were associated with the severity of pain in endometriosis patients $(p<0.05)$. Consequently, analyzing differences in the relative levels of four types of ERa splice variant in the endometrium of patients with endometriosis may help in the development of endometriosis-targeted treatment and the development of appropriate therapies.

\section{INTRODUCTION}

Endometriosis, defined as the presence of uterine stroma and glands outside of the uterine cavity, is one of the most prevalent disorders of the female reproductive tract [1]. The key symptom of endometriosis is pain, including dysmenorrhea, deep dyspareunia, and chronic pelvic pain. The burden of endometriosis has significant economic consequences within the healthcare system [2] and can influence the patient's daily quality of life, including sexual activity, emotional interaction, social activity, family relationships, and performance at work [3]. The pathophysiology of this disease, and its mechanisms in which this condition generates pain, are very unclear.

Estrogen has been recognized as an important factor in the pathogenesis of endometriosis [4]. Moreover, 
the role and interplay of estrogen receptors (both estrogen receptor alpha and beta [ER $\alpha$ and $E R \beta])$, and their associated splice variants, are increasingly being recognized as playing pivotal roles in estrogen-dependent diseases such as breast cancer [5].

$\mathrm{ER} \alpha$ is a ligand-dependent transcription factor involved in a wide spectrum of biological processes in both normal and neoplastic tissues. ER $\alpha$ is found on chromosome $6 \mathrm{q}$ and encodes for a 595 amino acid protein [6]. Upon binding estrogen (E), ER $\alpha$ dimerizes to promote strong binding of the E:ER complex to estrogen response elements, the specific DNA target of ER $\alpha$, thus initiating the transcription of target genes [7]. In the absence of E, $\mathrm{ER} \alpha$ is thought to be associated with a protein complex, including heat-shock proteins such as HSP-90 [8].

Alternative splicing is an important mechanism underlying transcript variation and is sometimes referred to as exon-skipping in which multiple forms of mRNA are generated from a common pre-mRNA via the differential use of exonic DNA. A growing body of evidence suggests that some ER $\alpha$ splice variants play an important role in both maintaining normal physiology and influencing susceptibility to a variety of diseases, including breast cancer, endometrial cancer and Alzheimer's disease (AD).

The presence of ER $\alpha$ mRNA variants in breast cancer cell lines, as well as tissue from breast cancer patients, has been well established in the literature $[9,10]$. Constitutivelyactive ER $\alpha$ variants could result in the unregulated growth of estrogen-responsive tissue; an effect that would not be interrupted by anti-estrogens. A dominant negative ER with the wild-type ER $\alpha$ variant would complete for anti-estrogen binding, thus diminishing its effects upon tissue [11-13]. Estrogen and some selective ER modulators are known to stimulate proliferation of the endometrium, thus increasing the risk of endometrial carcinoma $[14,15]$.

While the role of ERs, and their splice variants, in estrogen-dependent disease is becoming more and more accepted, very little is known about the presence of ER $\alpha$ splice variants in the human endometrium. An earlier study identified ER $\alpha$-Del.4 and ER $\alpha$-Del.7 (representing ER $\alpha$ splice variants missing exons 4 and 7, respectively) in the human endometrium and also in endometrial carcinoma [16]. However, we know little about the distribution and expression of $\mathrm{ER} \alpha$ splice variants in the human endometrium, either with or without endometriosis.

Consequently, our present investigation aimed to identify $\mathrm{ER} \alpha$ splice variants in the endometrium and to quantify relative differences in expression in human endometrium with and without endometriosis.

\section{RESULTS}

\section{Basic clinical information}

In total, we recruited 58 patients between September 2015 and December 2015 at the Department of Gynecology and Obstetrics, International Peace Maternity and Child Health Hospital of Shanghai Jiao Tong University (Shanghai, China).

The mean age of patients with and without endometriosis were $34.93 \pm 9.25$ and $38.75 \pm 8.35$ years, respectively. We detected significant differences between endometriosis and non-endometriosis groups in terms of dysmenorrhea $(p<0.001)$, parity $(p=0.035)$, and the frequency of sexual activity $(p=0.034)$. However, we failed to observe any statistically significant differences between the two groups in terms of age, body mass index (BMI), blood pressure and heart rate. Further analysis also failed to detect statistically significant differences between the two groups when we considered age at menorrhea, education, occupation, residential status, smoking, alcohol intake, exercise and mode of delivery (Table 1).

\section{DNA sequencing and mRNA expression}

Analysis of ER $\alpha$ mRNA transcripts in samples of human endometrium, both with and without endometriosis, are presented in Figure 1. In addition to wild-type (wt) ER $\alpha$ mRNA, we successfully detected the mRNA of four different types of splice variant in the human endometrium. These represent splice variants lacked exon 2 (Del.2), lacking exon 4 (Del.4), exon 7 (Del.7) and exons 3 and 4 (Figure 2A, 2B).

\section{Expression of $E R \alpha$ and its splice variants in the human endometrium}

Q-PCR primers were designed to quantify the mRNA levels of wt-ER $\alpha$ and its four splice variants: Del.2, Del.4, Del.7 and Del.3,4. Our analyses showed that wt-ER $\alpha$ and all four splice variants were expressed in the human endometrium, both with and without endometriosis, and were all detectable throughout the menstrual cycle. Of all the $\mathrm{ER} \alpha$ sub-types, wt-ER $\alpha$ was consistently expressed at the highest level, while Del.2 was expressed at the lowest levels. Del.4, Del.7, and Del.3,4 were expressed abundantly in the human endometrium. There was significantly stronger expression of wt-ER $\alpha$ compared to that of Del2 $(p<0.001)$, Del4 $(p<0.001), \operatorname{Del} 7(p<0.001)$, and Del3,4 $(p<0.001)$ within the total sample population ( $n=58$; Figure 3$)$.

\section{Expression of ER $\alpha$ and its splice variants in human endometrium with and without endometriosis}

When the phase of the menstrual cycle was disregarded, there was a significantly diminished expression of Del.4 $(P=0.047)$ and Del.7 $(P=0.032)$ in the endometrium of patients with endometriosis compared with healthy endometrium. However, no significant difference was observed in terms of the expression of wt- 
Table 1: Clinical information of our patient cohort with and without endometriosis

\begin{tabular}{|c|c|c|c|}
\hline Clinical characteristic & Control $(n=28)$ & Endometriosis $(n=30)$ & $P$ value \\
\hline Age (y) & $38.75 \pm 9.25$ & $34.93 \pm 8.35$ & 0.085 \\
\hline Body mass index $\left(\mathrm{kg} / \mathrm{m}^{2}\right)$ & $22.49 \pm 4.46$ & $21.81 \pm 3.03$ & 0.473 \\
\hline Systolic pressure (mmHg) & $111.25 \pm 12.12$ & $109.57 \pm 11.10$ & 0.582 \\
\hline Diastolic blood pressure $(\mathrm{mmHg})$ & $76.71 \pm 9.63$ & $74.80 \pm 9.6$ & 0.455 \\
\hline Heart beats (times/min) & $72.18 \pm 9.89$ & $70.63 \pm 8.99$ & 0.53 \\
\hline Age at menarche $(y)$ & $13.86 \pm 1.30$ & $14.00 \pm 1.23$ & 0.662 \\
\hline Age at first intercourse (y) & $23.18 \pm 2.14$ & $24.3 \pm 4.67$ & 0.312 \\
\hline Pain score & $0.53 \pm 0.03$ & $5.7 \pm 0.21$ & $<0.001$ \\
\hline \multicolumn{4}{|l|}{ Highest education $(n)$} \\
\hline Middle school or less & 8 & 12 & Reference \\
\hline High school & 15 & 14 & 0.419 \\
\hline University or above & 5 & 4 & 0.282 \\
\hline Occupation & & & 0.284 \\
\hline Mental status & 17 & 14 & \\
\hline Physical status & 11 & 16 & \\
\hline \multicolumn{4}{|l|}{ Salary $\mathrm{RMB} / \mathrm{m}(n)$} \\
\hline$<5000$ & 4 & 5 & Reference \\
\hline $5000-20,000$ & 18 & 17 & 0.709 \\
\hline$>20000$ & 7 & 8 & 0.641 \\
\hline \multicolumn{4}{|l|}{ Residence $(n)$} \\
\hline Urban & 17 & 21 & 0.457 \\
\hline Rural & 11 & 9 & \\
\hline \multicolumn{4}{|l|}{ Smoker $(n)$} \\
\hline Never & 19 & 20 & Reference \\
\hline Former & 7 & 6 & 0.749 \\
\hline Current & 2 & 4 & 0.482 \\
\hline \multicolumn{4}{|l|}{ Alcohol use $(n)$} \\
\hline Less than monthly & 13 & 17 & reference \\
\hline Weekly-monthly & 10 & 6 & 0.216 \\
\hline Daily-weekly & 5 & 7 & 0.921 \\
\hline \multicolumn{4}{|l|}{ Regular exercise $(n)$} \\
\hline No & 19 & 17 & 0.380 \\
\hline Yes & 9 & 13 & \\
\hline \multicolumn{4}{|l|}{ Parity $(n)$} \\
\hline Nulliparous & 7 & 16 & 0.035 \\
\hline Parous & 21 & 14 & \\
\hline \multicolumn{4}{|l|}{ Cesarean delivery $(n)$} \\
\hline No & 14 & 5 & 0.094 \\
\hline Yes & 7 & 9 & \\
\hline \multicolumn{4}{|l|}{ Vaginal delivery $(n)$} \\
\hline No & 7 & 9 & 0.094 \\
\hline Yes & 14 & 5 & \\
\hline
\end{tabular}


Sexually active frequency (times/month)

$<5$

ER $\alpha$ when compared between patients with and without endometriosis (Figure 4).

\section{Cycle-dependent expression of ER $\alpha$ in the human endometrium}

Next, we compared the expression of wt-ER $\alpha$ and its splice variants in different phases of the menstrual cycle. These findings were independent of endometrial pathology (Figure 4) and were based on analysis involving control patients in the proliferative phase $(n=18)$, control patients in the secretory phase $(n=10)$, endometriosis patients in the proliferative phase $(n=22)$, and endometriosis patients in the secretory phase $(n=8)$.

In the group of healthy women, the expression of $\mathrm{ER} \alpha$ during the proliferative phase was significantly higher than that in the secretory phase $(p=0.021)$. Furthermore, during the proliferative phase, the expression of Del.4 $(p=0.014)$, Del.7 $(p=0.004)$ and Del.3,4 $(p=0.032)$ were significantly reduced in endometriosis patients compared with healthy patients. However, levels of ER $\alpha$ were not significant between the two groups (Figure 5).

\section{Ratio of wt-ER $\alpha$ to its splice variants}

Here, we set out to determine how the ratio of wt-ER $\alpha$ and its splice variants varies in the human endometrium during different phases of the menstrual cycle in patients with and without endometriosis. We did this by analyzing levels of wt- ER $\alpha$ and ER $\alpha /$ del.2, $\mathrm{ER} \alpha / \mathrm{del} .4$, ER $\alpha / \mathrm{del} .7$, and ER $\alpha / \mathrm{del} .3,4$ in proliferative and secretory phases and compared these results between patients with and without endometriosis. Only in the proliferative endometrium was the ratio between ER $\alpha$ and
$\mathrm{ER} \alpha / \mathrm{del} .4(P=0.032), \mathrm{ER} \alpha / \mathrm{del} .7(P=0.027)$, and ER $\alpha /$ del.3,4 $(P=0.035)$ significantly higher in endometriosis tissue than in the control group (Figure 6).

\section{Correlations between ER $\alpha$ and its splice variants with the severity of pain}

As pain is the most classical clinical characteristic of endometriosis, we also aimed to investigate whether an increased ratio of ER $\alpha$ to its splice variants was correlated with the severity of pain in endometriosis.

Our analysis showed that the ratio of ER $\alpha$ :Del.4 and ER $\alpha: D e l .3,4$ in the proliferative phase were positively correlated with dysmenorrhea pain score $(r=0.61, p=$ $0.0003, r=0.54, p=0.0023$, respectively). However, we did not find any significant correlation between the ratio of ER $\alpha$ :Del7 and the severity of dysmenorrhea (Figure 7).

\section{DISCUSSION}

\section{ER $\alpha$ splice variants in the endometrium with and without endometriosis}

Over the past decades, scholars of endometriosis have integrated several classical etiological models into a neoclassical perspective, which includes the notion that anatomical, genetic, epigenetic, and possibly environmental factors influence the risk of developing endometriosis $[17,18]$.

There has been considerable interest among researchers in targeting alternatively spliced estrogen receptors since they have been detected (along with wild type receptors) in virtually every estrogen-responsive tissue investigated, including the endometrium [19]. Owing to their presence

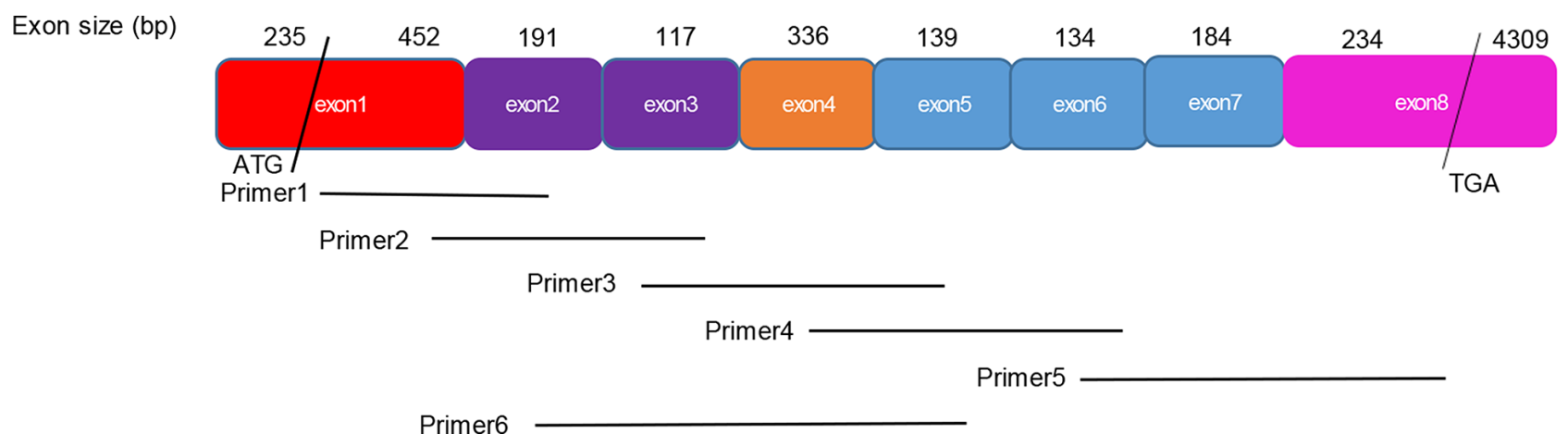

Figure 1: Structure of estrogen receptor alpha $(\mathrm{ER} \alpha)$ and primers designed for reverse-transcription polymerase chain reaction (RT-PCR) experiments. 
in normal tissues, it has been speculated that alternativelyspliced variants are naturally occurring molecules, and consequently may exert biological function in the estrogeninduced signal transduction processes as either positive or negative modulators of gene expression [20,21].

However, several questions remain unclear with regard to these splice variants. Firstly, prior to the present study, it was not known precisely which types of alternativelyspliced variants of the ER were expressed in the human endometrium. Secondly, we did not know whether alterations in the expression profile of these variants contributed to malignant transformation. Furthermore, it has not been established whether the relative expression of splice variants is related to the classical syndrome of endometriosis, especially in terms of the severity of dysmenorrhea.

To address some of the above questions, we used RT-PCR to identify several ER $\alpha$ splice variants in the human endometrium. WT-ER $\alpha$ was detected in all of the samples investigated, including those with and without endometriosis. Our data also showed that the ER $\alpha$ Del.2 variant was expressed at the lowest level of all variants, and in some samples was even undetectable, even by qPCR. This finding concurs with previous studies, which found minimal levels of ER $\alpha$ Del. 2 in a range of other tissues and conditions, including patients with Alzheimer's disease (AD) [19, 22]. In contrast, the other ER splice variants, ER $\alpha$ Del.4, ER $\alpha$ Del.7 and ER $\alpha$ Del.3,4, were expressed at much higher levels.

\section{Characteristics of ER $\alpha$ splice variants}

Functional studies in cell lines have provided evidence that the exon deletion variants detected in the present study (ER $\alpha$ Del.4, ER $\alpha$ Del.7 and ER $\alpha$ Del.2) are
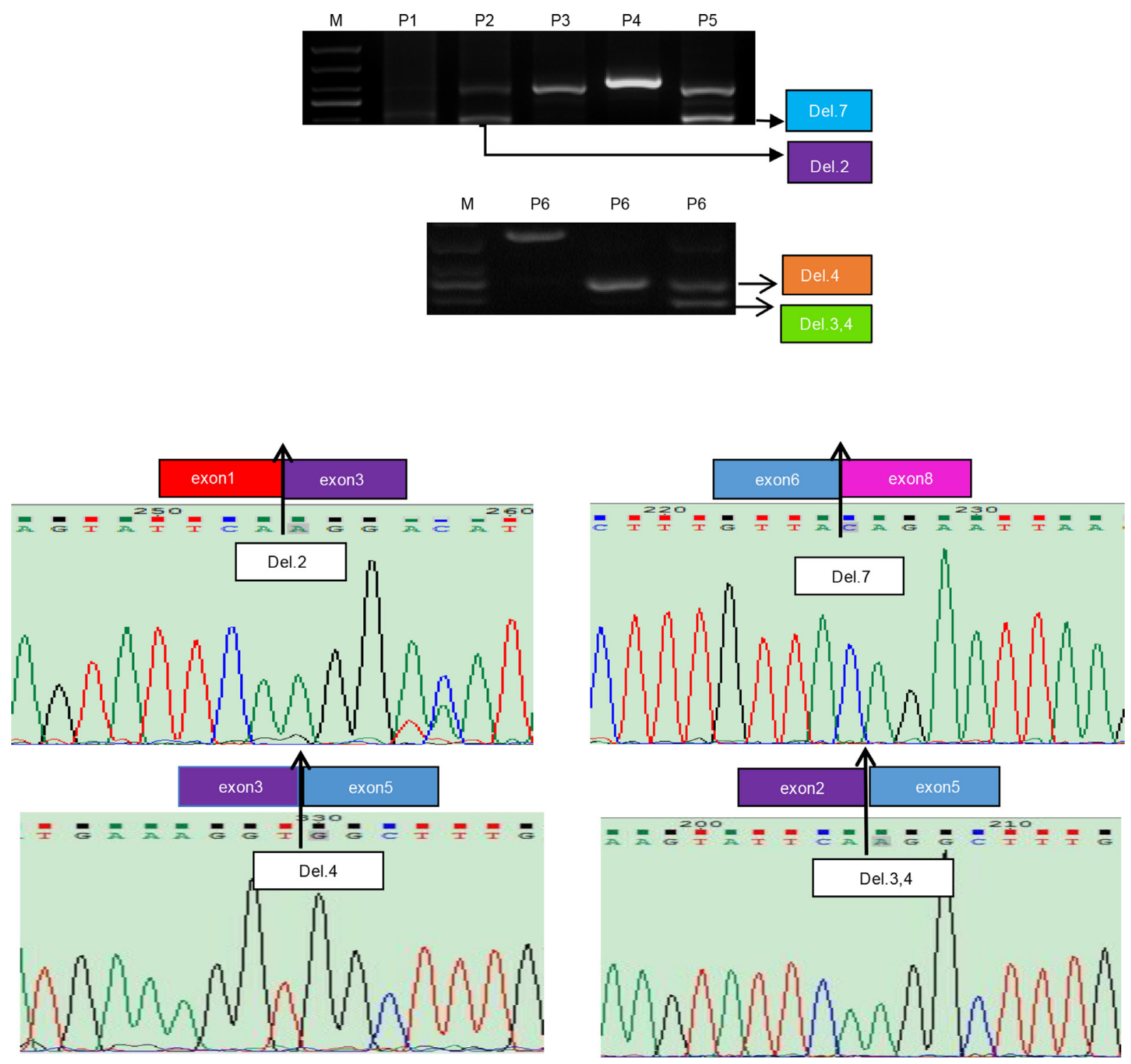

Figure 2: Identification of four estrogen splice variants in the human endometrium. Amplified polymerase chain reaction (PCR) products were purified from agarose gels, cloned and then sequenced. 
mainly localized in the cytoplasm [23-25]. Deletion of exon 4 suggests the loss of a portion of the ligand-binding domain and nuclear localization signal which explains the inability of ER $\alpha$ Del. 4 mutants to bind to estradiol and to estrogen-responsive elements [23].

While the nuclear localization of this variant has also been described previously, ER $\alpha$ Del. 4 is known to be loosely associated to the nuclear matrix and remains unaffected during hormonal treatment [23]. It is also worth noting that ER $\alpha$ Del.4 may also inhibit estrogenindependent transcriptional activity.

Deletion of exon 7 results in the deletion of 61 amino acids in the mature protein structure, indicating the loss of a significant portion of the hormone-binding domain and the ligand-binding domain with ligand-dependent transactivation function (AF2) [26]. Consequently, ER $\alpha$-Del.7

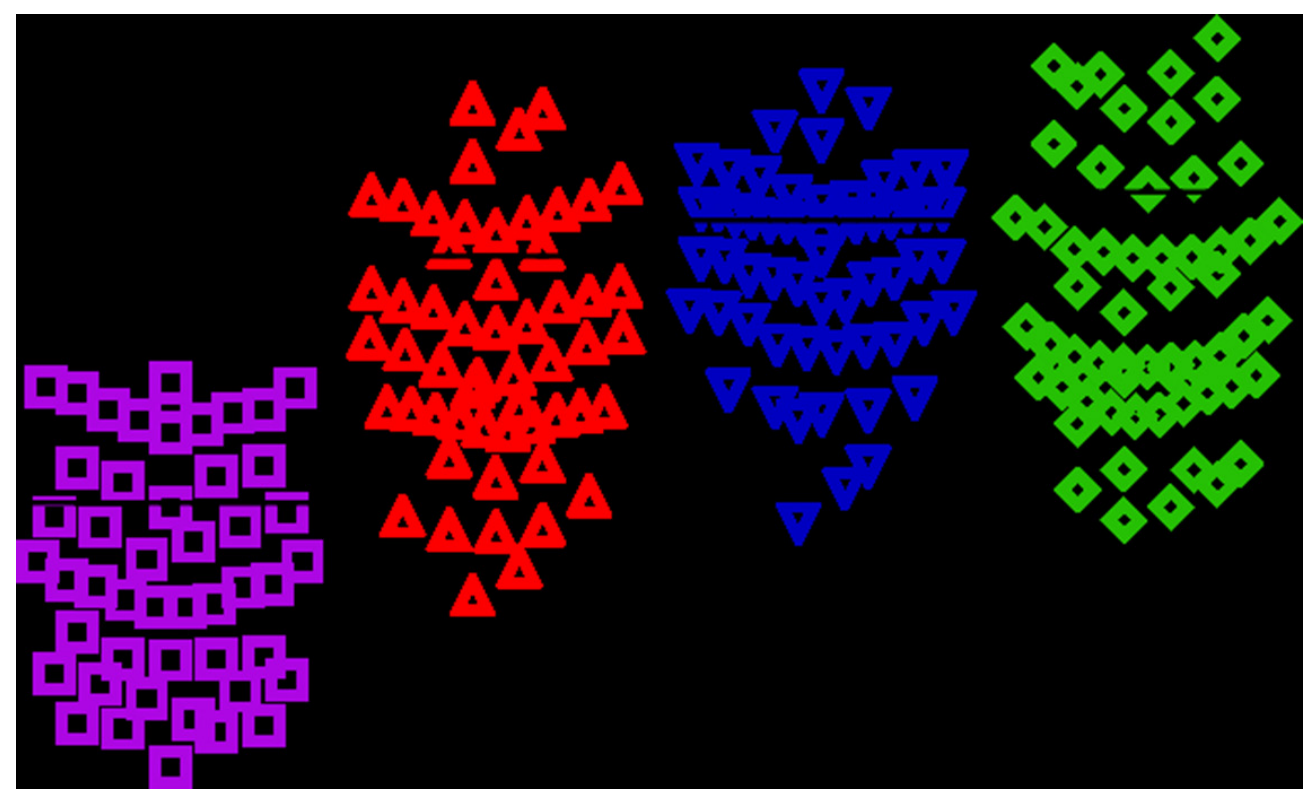

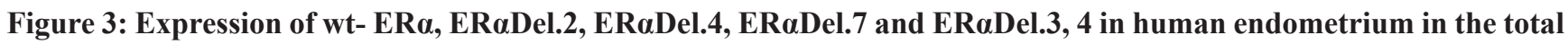
sample population ( $n=58$ patients) without taking into account the phase of the menstrual cycle or the existence of endometriosis. Data from three to six experiments are expressed on a logarithmic scale in relation to GAPDH and B-actin mRNA levels (mean \pm standard deviation). ${ }^{*} p<0.05,{ }^{* *} p<0.01$ in comparison with wt-ERa.

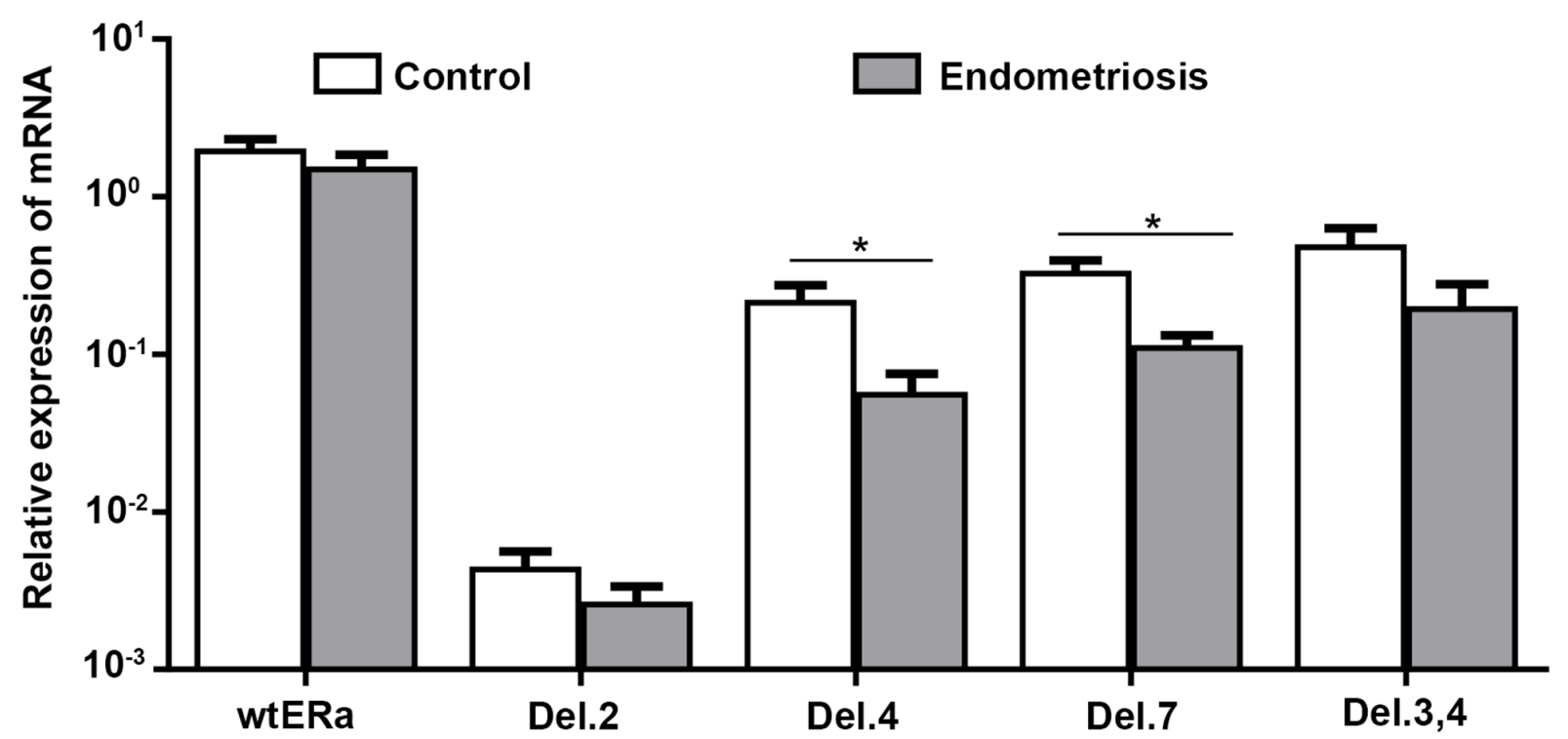

Figure 4: Expression of wt-ER $\alpha$, ER $\alpha$ Del.2, ER $\alpha$ Del.4, ER $\alpha$ Del.7 and ER $\alpha D e l .3,4$ in patients with $(n=30)$ and without endometriosis (control, $\boldsymbol{n}=\mathbf{2 8}$ ), without taking into account the phase of the menstrual cycle. When cycle phase was ignored, the expression of ER $\alpha$ Del.4 and ER $\alpha$ Del.7 are significantly different between patients with and without endometriosis. Data from three to six experiments are expressed in logarithmic scale in relation to GAPDH mRNA levels (mean values \pm standard deviation), ${ }^{*} p<$ $0.05,{ }^{* *} p<0.01$. 
cannot bind ligands, is insensitive to estrogens and antiestrogens, and cannot associate with coactivators.

The exon 7 deletion protein has been reported to bind DNA in vivo and has been reported to act as dominant-negative. Due to its ability to form heterodimers with both of the classical estrogen receptors, ER $\alpha$ and ERß, the ER $\alpha$ Del.7 variant results in a significant reduction of estrogen signaling in various cell types and may protect tissues from the effects of excessive estrogen.

High levels of ER $\alpha$ Del.7 in the endometrium, as found in our present study, concurs with previous literature describing the excessive expression of this isoform in the pituitary mammillary body, prefrontal cortex, lung, breast, and peripheral blood mononuclear cells [27-29]. However, little is known about the relative expression of the ER $\alpha$ Del.3,4 variant.

\section{ER $\alpha$ splice variants and endometriosis}

Estrogens and steroid hormones play a primary function in the development and regulation of the female and male reproductive system. The classical signaling pathway involves estrogen receptors binding to ligands, translocating from the cytosol to the nucleus, dimerizing, recruiting other transcription modulating factors, and interacting with DNA promoter regions to influence transcription. The primary ligand for the human ER is E2, the predominant form of estrogen in premenopausal women.

For several decades, investigators have rigorously examined the role of ERs in the pathogenesis of disease. Much of this work has been conducted in the absence of specific attention to ER splice variants and how they might modify the physiological and pathological roles of E2 as a multifunctional tissue hormone. However, there is a growing body of evidence to suggest that some splice variants play an important role in both maintaining normal physiology and influencing susceptibility to disease. Compared with full-length "parent" receptors, splice variants differ in terms of the actions they mediate as a consequence of the lack of (or different configuration of) various receptor domains. Resultant splice variants may therefore fail to bind ligands, fail to translocate to the nucleus, fail to dimerize, or exhibit altered

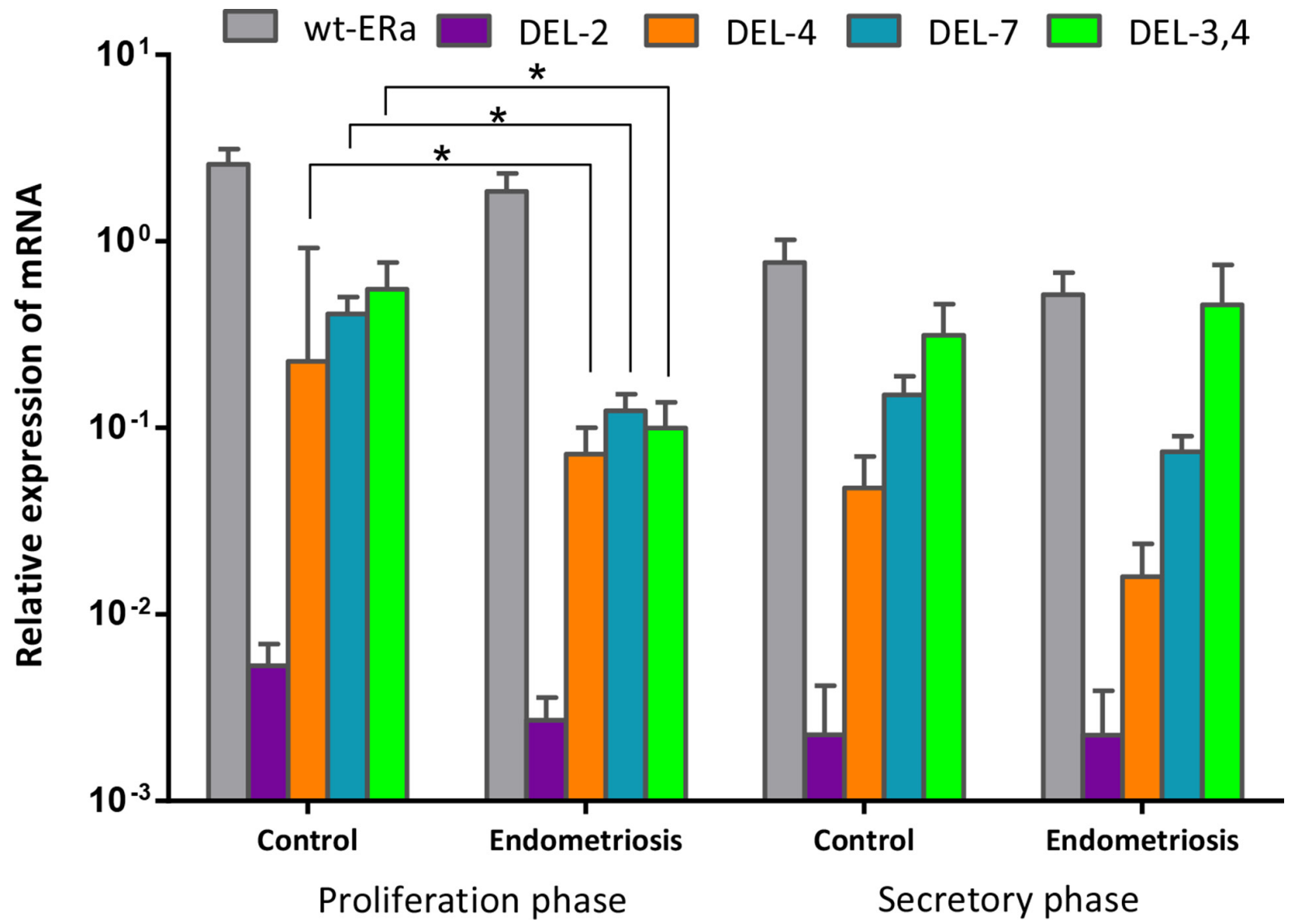

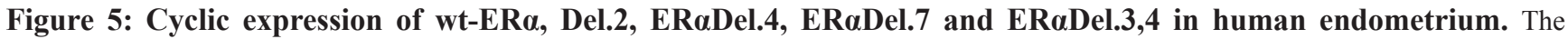
expression of wt-ER $\alpha$ and its splice variants were compared between four groups of patients characterized by cycle phase (proliferative and secretory phase) and the existence of endometriosis (healthy control patients vs. patients with endometriosis (control patients in the proliferative phase $n=18$, control patients in the secretory phase $n=10$, patients with endometriosis in the proliferative phase $n=22$, patients with endometriosis in the secretory phase $n=8$ ). Data from three to six experiments are expressed on a logarithmic scale in relation to GAPDH mRNA levels (mean \pm standard deviation). ${ }^{*} p<0.05,{ }^{* *} p<0.01$. 
cofactor recruitment or the failure to bind and stimulate transcription at ERE or AP1 sites. If a splice variant fails to carry out these functions, it is unlikely that it will have any effect upon cell function. However, by failing to effectively perform one or two of these functions, inhibition of the full-length receptor may occur due to competitive ligand binding, heterodimer formation with the full-length formation receptor (rendering it inactive) and DNA binding without transcription (preventing the full length receptor from gaining appropriate access).

The function of ER $\alpha$ splice variants in the pathology of many diseases is not clearly defined. In most cases, this role is not yet fully understood and it is possible that ER splice variants could play a part. However, interestingly, it is possible that the dominant negative-function of $\mathrm{ER} \alpha$ splice variants might protect tissues from excessive estrogenic signals. Furthermore, when the concentration of $\mathrm{ER} \alpha$ splice variants declines in the endometrium, it is possible that the tissue may be exposed to more estrogenic signals. As we know, excessive estrogen plays an important role in the development and progression of endometriosis, which may help us to understand the role of $\operatorname{ER} \alpha$ splice variants in the pathology of endometriosis.

\section{Ratio of wtER $\alpha$ to its splice variants and dysmenorrhea}

The most common and most specific symptom of endometriosis is pain, typically in the form of progressive, secondary dysmenorrhea. This pain may also manifest as dyspareunia, dysuria, or dyschezia, or be referred to musculoskeletal regions, such as the flank or low back. The nature of the pain associated with endometriosis has been characterized inadequately, and the mechanisms involved remain unclear. Recent studies in both human and animal models suggest that the action of estrogen exacerbates pain sensitivity by stimulating the growth of a nerve supply (neurogenesis) [30], in parallel with the growth of new blood vessels (angiogenesis) into the ectopic endometrial tissue [30, 31].

Interestingly, in our present study, we observed high ratios of wt-ER $\alpha: E R \alpha D e l 4, w t-E R \alpha: E R \alpha D e l .7$, and wt-ER $\alpha: E R \alpha D e l .3,4$ in patients with endometriosis, which indicates that relatively more wt-ER $\alpha$ existed in endometriotic tissues and were thus exposed to more functional E2. Furthermore, the ratios of wtER $\alpha: E R \alpha D e l .4$ and wt-ER $\alpha: E R \alpha D e l .3,4$ were positively correlated with the severity of pain syndrome. In endometriosis patients, the relatively high ratio of wt$\mathrm{ER} \alpha$ to its associated splice variants, may provide an explanation for the promotion of both neurogenesis and angiogenesis and in the induction of dysmenorrhea.

\section{Summary}

In summary, we identified a range of ER $\alpha$ variants in the human endometrium and compared the relative levels of expression of these splice variants in relation to the wtER $\alpha$ during different phases of the menstrual cycle. The specific expression of ER $\alpha$-isoforms varied according to

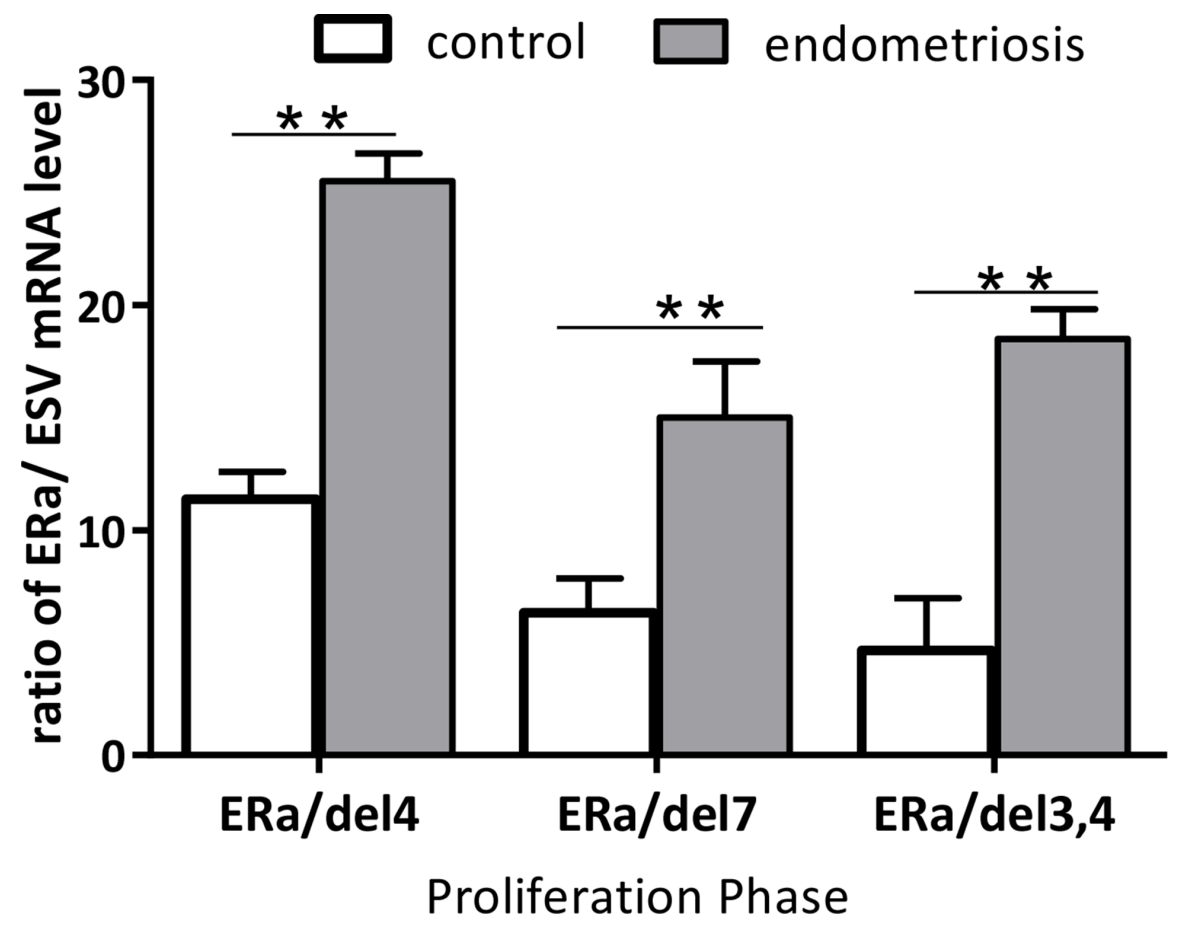

Figure 6: In the proliferative phase, the ratio of wt-ER $\alpha: E R \alpha$ EL.4, wt-ER $\alpha: E R \alpha D E L .7$ and wt-ER $\alpha: E R \alpha D E L .3,4$ were significantly higher in endometriosis patients compared with the control group. Data from three to six experiments were pooled and the ration of wt-ER $\alpha$ and its respective splice variants are shown as mean values \pm standard deviation. ${ }^{*} p<0.05,{ }^{* *} p<0.01$. 
the phase of the menstrual cycle and whether the patient had endometriosis. The expression of ER $\alpha$ splice variants was significantly reduced in patients with endometriosis. Furthermore, the ration of wt-ER $\alpha$ to its splice variants was significantly higher in patients with endometriosis and correlated positively with the severity of pain.

Our present study may therefore provide a new direction for further studies in the pathology of endometriosis-associated pain, and may hold significant promise for the improvement of endometriosis targetedtreatment and medicine development.

\section{MATERIALS AND METHODS}

A total of 58 women voluntarily participated in this study. Written consent was provided by all women and the study was approved by the Institutional Review Committee of the International Peace Maternity and Child Health Hospital, School of Medicine, Shanghai Jiao Tong University. None of the participants had pelvic inflammatory disease or cancer, and none had received any hormonal therapies during the 3 months leading up to the study.

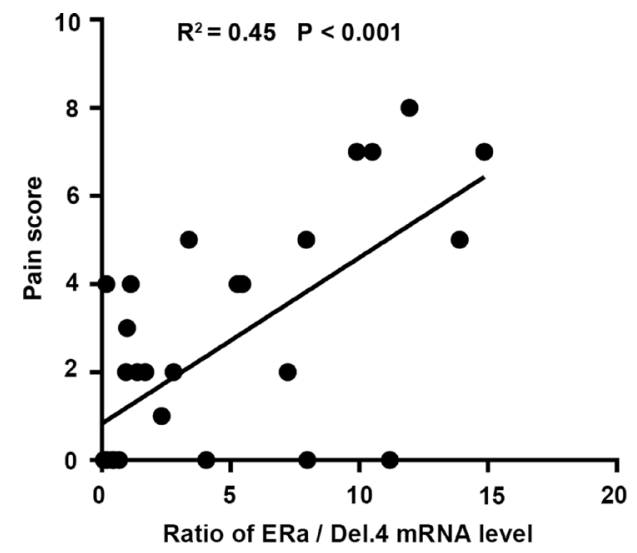

The diagnosis of endometriosis was confirmed by visual impression at the time of surgery and histological examination of resected lesions. Endometriosis was scored and staged according to the revised classification system of the American Fertility Society (Society, 1985). All endometriosis patients were in severe stage, stage III-IV. Twenty-eight endometrium specimens were collected from healthy fertile women undergoing tubal sterilization and without any evidence of endometriosis at laparoscopy; these subjects formed our control group. Menstrual cycle phase was determined by the patient's last menstrual period and confirmed by histological dating of the endometrium. The intensity of pelvic pain symptoms just before surgery was assessed with a $10-\mathrm{cm}$ visual analogue scale (VAS).

\section{RNA isolation}

Total RNA was isolated from frozen endometrium samples using a Purelink RNA Mini Kit (ThermoFisher, Foster City, CA). All RNA was tested by spectrophotometric analysis on a Nanodrop 2000 (ThermoFisher, Foster City, CA) at absorbances of $260 \mathrm{~nm}$

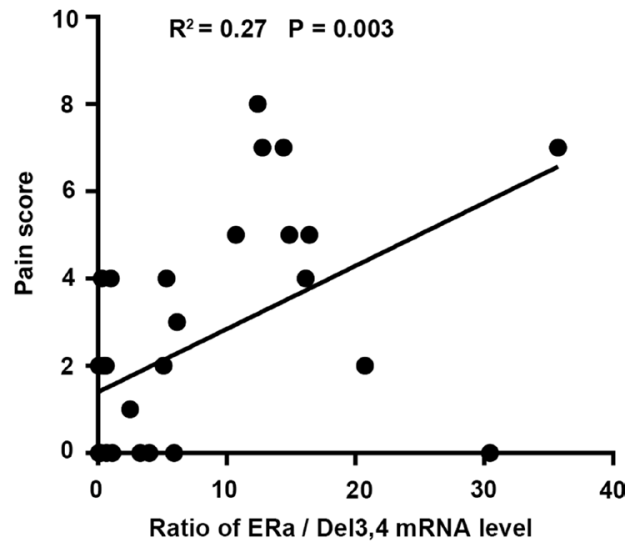

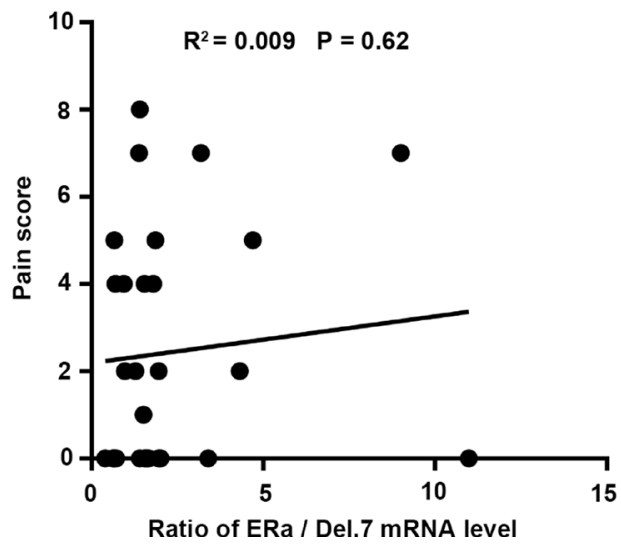

Figure 7: Correlation between the ratio of wt-ER $\alpha$ and its respective splice variants with dysmenorrhea pain score, which was assessed using the visual analogue scale (VAS) of $0-10$ in endometriosis patients. The ratios of wt-ER $\alpha$ :DEL.4 and wt-ER $\alpha: D E L .3,4$ were positively correlated with the dysmenorrhea pain score ( $r=0.61, p=0.0003$ and $r=0.54, p=0.0023$, respectively), although there was no significant correlation between the ratio of wt-ER $\alpha: E R \alpha$ Del.7 and dysmenorrhea pain score. 
and $280 \mathrm{~nm}$, thus allowing calculation of the $260 \mathrm{~nm}: 230$ $\mathrm{nm}$ ratio. RNA was then reverse transcribed into cDNA using the Superscript IV First-Strand Synthesis System (ThermoFisher Scientific, Waltham, MA) in accordance with the manufacturer's instructions.

\section{Reverse transcription PCR (RT-PCR), cloning and DNA sequencing}

RT- PCR was performed in $20 \mu \mathrm{l}$ of PCR mixture comprising cDNA corresponding to $1 \mu \mathrm{g}$ of total RNA, $1 \times$ PCR buffer, $0.2 \mathrm{mM}$ dNTP mixture, and $0.2 \mathrm{M}$ of forward and reverse primers, along with $0.25 \mathrm{U}$ of Q5 Hot Start High-Fidelity DNA polymerase (NEB, UK). PCR was performed with cycle reactions of $95^{\circ} \mathrm{C}$ for $5 \mathrm{~s}, 60^{\circ} \mathrm{C}$ for $30 \mathrm{~s}$, and $72^{\circ} \mathrm{C}$ for $60 \mathrm{~s}$, with an initial denaturing step of $95^{\circ} \mathrm{C}$ for $2 \mathrm{~min}$ and a final elongation step of $72^{\circ} \mathrm{C}$ for $2 \mathrm{~min}$. The sequences of the oligonucleotide primers used for RT-PCR are shown in Supplementary Tables 1 and 2.

Amplified PCR products were then selected from $2 \%$ agarose gels and ER products characterized by cloning the gel-purified products into the pCR2.1-TOPO vector and DNA sequence analysis, as described previously (Majorbio Company, Shanghai, China).

\section{Real-Time PCR}

Real-time PCR was carried out using a QuantiNova SYBR Green PCR kit (QIAGEN, Shanghai, China) in accordance with the manufacturer's instructions and by using an initial denaturation step at $95^{\circ} \mathrm{C}$ for $2 \mathrm{~min}$, followed by 40 cycles with $10 \mathrm{~s}$ denaturation at $95^{\circ} \mathrm{C}$ and $30 \mathrm{~s}$ annealing at $60^{\circ} \mathrm{C}$. PCR was carried out in an Applied Biosystems 7900 Real-Time PCR system (AB Applied Biosystems, Foster City, CA) by standard melting curve analysis. Negative controls were prepared by adding distilled water instead of the DNA template. The identity of the PCR products was verified by electrophoresis in $2 \%$ agarose gels and stained with $1 \mu$ l GelRed (Biosharp, Shanghai, China). After assessing molecular weight, each PCR product was purified using the Takara MiniBEST Agarose Gel DNA Extraction Kit v4.0 (Takara, Shiga, Japan), following the manufacturer's protocol, and finally verified by DNA sequencing (Majorbio Company, Shanghai, China).

In all RT-PCR experiments, a 142-bp GAPDH fragment was amplified as a reference housekeeping gene using the intron spanning primers, GAPDH-347 (GCACCGTCAAGGCTGAGAAC) and GAPDH-488 (ATGGTGGTGAAGACGCCAGT). Data were analyzed using the comparative $\triangle \triangle \mathrm{CT}$ method, which calculates the difference between threshold cycle (CT) values of the target and reference genes from each sample and then compares the resulting $\Delta \mathrm{CT}$ values between different samples.

\section{Statistical analysis}

For descriptive statistics, data are presented as the mean \pm standard deviation, and for categorical variables as counts or frequencies with percentages or proportions. The Student's $t$-test was used to evaluate differences between sample groups for normally distributed data, while the Mann-Whitney $U$ test was used for non-parametric variables.

Correlations between the number of positive domains and symptom severity were assessed by Spearman's coefficient of rank correlation. All statistical assessments were two-tailed and were considered significant when $p<0.05$. All data analysis was performed using SPSS (v16.0 for Windows) statistical software (SPSS Inc., Chicago, IL).

\section{CONFLICTS OF INTEREST}

The authors declare that they have no conflicts of interest.

\section{FUNDING}

This work was supported by Major Program of National Natural Science Foundation of China (81490742), The National Key Research and Development Program of China ( 2017YFC1001303 ), National Natural Science Foundation of China (31471405, 81601238, 81501274 and 81671456), International Cooperation Project of China and Canada NSFC ( 81661128010 ), The Interdisciplinary Key Program of Shanghai Jiao Tong University ( YG2014ZD08), Shen Kang Three Year Action plan (16CR3003A ), Shanghai Municipal Commission of Health and Family Planning (201540084, 20164Y0251).

\section{REFERENCES}

1. Agarwal N, Subramanian A. Endometriosis - morphology, clinical presentations and molecular pathology. J Lab Physicians. 2010; 2:1-9.

2. Gao X, Outley J, Botteman M, Spalding J, Simon JA, Pashos CL. Economic burden of endometriosis. Fertil Steril. 2006; 86:1561-1572.

3. Zevallos HB, McKinnon B, Tokushige N, Mueller MD, Fraser IS, Bersinger NA. Detection of the pan neuronal marker PGP9.5 by immuno-histochemistry and quantitative PCR in eutopic endometrium from women with and without endometriosis. Arch Gynecol Obstet. 2015; 291:85-91.

4. Reis FM, Petraglia F, Taylor RN. Endometriosis: hormone regulation and clinical consequences of chemotaxis and apoptosis. Hum Reprod Update. 2013; 19:406-418.

5. Kampa M, Pelekanou V, Notas G, Stathopoulos EN, Castanas E. The estrogen receptor: two or more molecules, multiple variants, diverse localizations, signaling and functions. Are 
we undergoing a paradigm-shift as regards their significance in breast cancer? Hormones (Athens). 2013; 12:69-85.

6. Evans RM. The steroid and thyroid hormone receptor superfamily. Science. 1988; 240:889-895.

7. Kumar V, Chambon P. The estrogen receptor binds tightly to its responsive element as a ligand-induced homodimer. Cell. 1988; 55:145-156.

8. Beato M. Gene regulation by steroid hormones. Cell. 1989; $56: 335-344$.

9. Murphy LC. Estrogen receptor variants in human breast cancer. Mol Cell Endocrinol. 1990; 74:C83-86.

10. Zhang QX, Hilsenbeck SG, Fuqua SA, Borg A. Multiple splicing variants of the estrogen receptor are present in individual human breast tumors. J Steroid Biochem Mol Biol. 1996; 59:251-260.

11. Pfeffer U, Fecarotta E, Castagnetta L, Vidali G. Estrogen Receptor Variant Messenger RNA Lacking Exon 4 in Estrogen-responsive Human Breast Cancer Cell Lines. Cancer Research. 1993; 53:741-743.

12. Koehorst SGA, Cox JJ, Donker GH, da Silva SL, Burbach JPH, Thijssen JHH, Blankenstein MA. Functional analysis of an alternatively spliced estrogen receptor lacking exon 4 isolated from MCF-7 breast cancer cells and meningioma tissue. Molecular and Cellular Endocrinology. 1994; 101:237-245.

13. Madsen MW, Reiter BE, Lykkesfeldt AE. Differential expression of estrogen receptor mRNA splice variants in the tamoxifen resistant human breast cancer cell line, MCF7/TAMR-1 compared to the parental MCF-7 cell line. Mol Cell Endocrinol. 1995; 109:197-207.

14. Altaras MM, Aviram R, Beyth Y. Tamoxifen-associated endometrial carcinoma in postmenopausal breast cancer patients. Gynecol Oncol. 1991; 41:270.

15. Fujimoto J, Hori M, Ichigo S, Nishigaki M, Itoh T, Tamaya T. Expression of aberrant estrogen receptor mRNA in endometrial cancers in comparison with normal endometria. Horm Res. 1994; 42:116-119.

16. Hirata S, Yamada-Mouri N, Nara M, Takizawa M, Ito H, Kato J. Presence of alternatively spliced-estrogen receptor mRNA variants in normal human uterine endometrium and endometrial cancer. Endocr J. 1995; 42:289-293.

17. Vercellini P, Vigano $\mathrm{P}$, Somigliana E, Fedele L. Endometriosis: pathogenesis and treatment. Nat Rev Endocrinol. 2014; 10:261-275.

18. Kitawaki J, Kado N, Ishihara H, Koshiba H, Kitaoka Y, Honjo H. Endometriosis: the pathophysiology as an estrogen-dependent disease. J Steroid Biochem Mol Biol. 2002; 83:149-155.

19. Taylor SE, Martin-Hirsch PL, Martin FL. Oestrogen receptor splice variants in the pathogenesis of disease. Cancer Lett. 2010; 288:133-148.
20. Denger S, Reid G, Kos M, Flouriot G, Parsch D, Brand H, Korach KS, Sonntag-Buck V, Gannon F. ERalpha gene expression in human primary osteoblasts: evidence for the expression of two receptor proteins. Mol Endocrinol. 2001; 15:2064-2077.

21. Poola I, Speirs V. Expression of alternatively spliced estrogen receptor alpha mRNAs is increased in breast cancer tissues. J Steroid Biochem Mol Biol. 2001; 78:459-469.

22. Moutsatsou P, Kassi E, Creatsas G, Coulocheri S, Scheller $\mathrm{K}$, Sekeris CE. Detection of oestrogen receptor variants in endometrium, myometrium, leiomyoma and peripheral blood mononuclear cells: comparison to variants present in breast cancer. J Cancer Res Clin Oncol. 1998; 124:478-484.

23. Park W, Choi JJ, Hwang ES, Lee JH. Identification of a variant estrogen receptor lacking exon 4 and its coexpression with wild-type estrogen receptor in ovarian carcinomas. Clin Cancer Res. 1996; 2:2029-2035.

24. Koehorst SG, Cox JJ, Donker GH, Lopes da Silva S, Burbach JP, Thijssen JH, Blankenstein MA. Functional analysis of an alternatively spliced estrogen receptor lacking exon 4 isolated from MCF-7 breast cancer cells and meningioma tissue. Mol Cell Endocrinol. 1994; 101:237-245.

25. Koduri S, Goldhar AS, Vonderhaar BK. Activation of vascular endothelial growth factor (VEGF) by the ERalpha variant, ERDelta3. Breast Cancer Res Treat. 2006; 95:37-43.

26. Horvath G, Leser G, Helou K, Henriksson M. Function of the exon 7 deletion variant estrogen receptor alpha protein in an estradiol-resistant, tamoxifen-sensitive human endometrial adenocarcinoma grown in nude mice. Gynecol Oncol. 2002; 84:271-279.

27. Villa E, Camellini L, Dugani A, Zucchi F, Grottola A, Merighi A, Buttafoco P, Losi L, Manenti F. Variant estrogen receptor messenger RNA species detected in human primary hepatocellular carcinoma. Cancer Res. 1995; 55:498-500.

28. Chaidarun SS, Alexander JM. A tumor-specific truncated estrogen receptor splice variant enhances estrogenstimulated gene expression. Mol Endocrinol. 1998; 12:1355-1366.

29. Shupnik MA, Pitt LK, Soh AY, Anderson A, Lopes MB, Laws ER Jr. Selective expression of estrogen receptor alpha and beta isoforms in human pituitary tumors. J Clin Endocrinol Metab. 1998; 83:3965-3972.

30. Asante A, Taylor RN. Endometriosis: the role of neuroangiogenesis. Annu Rev Physiol. 2011; 73:163-182.

31. Greaves E, Collins F, Esnal-Zufiaurre A, Giakoumelou S, Horne AW, Saunders PT. Estrogen receptor (ER) agonists differentially regulate neuroangiogenesis in peritoneal endometriosis via the repellent factor SLIT3. Endocrinology. 2014; 155:4015-4026. 